\title{
$\begin{array}{lllll}\text { I } & \mathbf{N} & \mathbf{D} & \mathbf{E} & \mathbf{X}\end{array}$ \\ T I T $\mathbf{T}$ U
}

I. De libertis.

II. De statu libero [vel statu liberis] *

III. De Latinis.

IV. De his qui sui iuris sunt.

v. De his qui in potestate sunt.

vI. De dotibus.

VII. De iure donationum inter virum et uxorem.

VIII. De adoptionibus.

IX. De his qui 2 in manu sunt.

X. Qui in potestate mancipiove sunt quem admodum eo iure liberentur.

XI. De tutelis.

XII. De curatoribus.

XIII. De coelibe ${ }^{3}$ orbo et solitario patre.

2) C. de statu liberū vel statu liberis Hugo: de statu liberis; sed idem infra restituit codicis lectionem. [Bluntschlj codicis scripturam secuturus fuit; cum F. A. Schillingio (animadvv. critt. ad Ulp. spec. I. II. Lips. 1830. 80) scripsi libero pro liber ü. Bg.] |²) BI. veteres quosdam editores secutus scripserat quae. sed emendatione non opus est. Bg.] ' 3) Cod. Decele. 


\section{INDEX TITULORUM.}

XIV. De poena legis Iuliae.

XV. De decimis.

XVI. De solidi capacitate inter viram et uxorem.

XVII. De caducis.

XVIII. Qui habeant ius antiqum in caducis.

XIX. De dominiis et adquisitionibus rerum.

XX. De testamentis.

XXI. Quemadmodum heres institui debeat.

XXII. Qni heredes institui possunt.

Cod:Vat.XXIII. Quemadmodum testamenta rumpuntur.

f. 191.acc.XXIV. De legatis.

XXV. De fideicommissis.

XXVI. De leyitimis heredibus.

XXVII. De libertorum successionibus ral bonis.

XXVIII. De possessionibus dandis.

XXIX. De bonis libertorum. 